\title{
Climatological Estimates of Daily Local Nontornadic Severe Thunderstorm Probability for the United States
}

\author{
Charles A. Doswell III \\ Cooperative Institute for Mesoscale Meteorological Studies, University of Oklahoma, Norman, Oklahoma \\ HAROLD E. BROOKS \\ NOAA/National Severe Storms Laboratory, Norman, Oklahoma \\ MichaEl P. KAY* \\ Cooperative Institute for Mesoscale Meteorological Studies and NOAA/Storm Prediction Center, Norman, Oklahoma
}

(Manuscript received 20 July 2004, in final form 18 January 2005)

\begin{abstract}
The probability of nontornadic severe weather event reports near any location in the United States for any day of the year has been estimated. Gaussian smoothers in space and time have been applied to the observed record of severe thunderstorm occurrence from 1980 to 1994 to produce daily maps and annual cycles at any point. Many aspects of this climatology have been identified in previous work, but the method allows for the consideration of the record in several new ways. A review of the raw data, broken down in various ways, reveals that numerous nonmeteorological artifacts are present in the raw data. These are predominantly associated with the marginal nontornadic severe thunderstorm events, including an enormous growth in the number of severe weather reports since the mid-1950s. Much of this growth may be associated with a drive to improve warning verification scores. The smoothed spatial and temporal distributions of the probability of nontornadic severe thunderstorm events are presented in several ways. The distribution of significant nontornadic severe thunderstorm reports (wind speeds $\geq 65 \mathrm{kt}$ and/or hailstone diameters $\geq 2$ in.) is consistent with the hypothesis that supercells are responsible for the majority of such reports.
\end{abstract}

\section{Introduction}

The climatology of severe weather is an important component in severe weather forecasting and research. With the introduction of probabilistic forecasting of severe convective storms by the Storm Prediction Center (SPC), baseline climatological frequencies were needed to develop actual daily forecast probabilities. Further, various private sector and governmental planning ef-

\footnotetext{
* Current affiliation: Cooperative Institute for Research in Environmental Sciences, University of Colorado, and NOAA/ Forecast Systems Laboratory, Boulder, Colorado.
}

Corresponding author address: Dr. Charles A. Doswell III, CIMMS, 100 East Boyd St., Rm. 1110, University of Oklahoma, Norman, OK 73019.

E-mail: cdoswell@gcn.ou.edu forts depend in part on knowing the average frequencies of severe weather. In response to these needs, Brooks et al. (2003, hereafter BDK03) presented a method for producing a smoothed tornado frequency from the very noisy raw data. We are herein considering the application of comparable tools to the problem of nontornadic severe thunderstorm reports. An important requirement for the work in BDK03 was to develop climatological frequencies compatible with the forecast products produced by the SPC. This paper shares the same motivations.

Officially in the United States, a nontornadic severe thunderstorm event is defined as any of the following: (a) a convective wind gust $\geq 50 \mathrm{kt}\left(25 \mathrm{~m} \mathrm{~s}^{-1}\right),{ }^{1}$ (b) an

\footnotetext{
${ }^{1}$ Since the raw data are measured in non-Système Internationale (SI) units, they will be used throughout, but metric equivalents have been included here.
} 
unmeasured wind gust that produces damage (considerable subjectivity is involved in determining the intensity of the wind that produces observed damage), or (c) hail with a diameter $\geq 3 / 4$ in. $(2 \mathrm{~cm}$ ). In the past (as described in Doswell 1985), damage produced by unmeasured convective winds was expected to meet certain criteria; damage of a minor nature (such as leaves and twigs being blown off trees) would not have constituted a severe convective wind event. That is, the observed damage associated with a convective windstorm was to be consistent with the damage potential of winds equaling or exceeding $50 \mathrm{kt}$. Of late, the local National Weather Service (NWS) offices have been given complete responsibility to make this subjective decision. Using the earlier criteria, Kelly et al. (1985) provided a review of the nontornadic severe thunderstorm climatology comparable to that for a tornado climatology done by Kelly et al. (1978). This change in philosophy regarding the archiving of severe thunderstorm reports is one of many, and while it surely has had an impact on the data, the magnitude of this particular change is impossible to isolate from all the other factors, some of which we will illustrate in what is to follow.

Reports of severe thunderstorm events are archived at the SPC and constitute the database that was used for this study. This database is described elsewhere (Kelly et al. 1985; Hales 1993; Schaefer and Edwards 1999). It should be noted that reports of severe weather in the SPC database are point reports, whereas the actual wind and hail events are best characterized as swaths of wind and/or hail having diverse geometrical properties. Unfortunately, these properties are not generally observable and, hence, are not typically reported. Unlike tornado tracks, which are characterized as having a length and a width, nontornadic severe events are simply point events. According to earlier SPC criteria (discussed in Doswell 1985), reports of nontornadic severe thunderstorm events had to be separated by at least $10 \mathrm{mi}(16 \mathrm{~km})$ and $15 \mathrm{~min}$. Exceptions to this were the following: (a) all tornadoes are documented as separate events (multiple suction vortices are logged as one event); (b) significant severe weather events involving injuries, deaths, and/or spectacular damage were logged, regardless of time and distance to an earlier event (which might be done by replacing an earlier event with a more significant event or by adding significant event notations to the previously logged event); and (c) all officially measured convective wind gusts were logged regardless of space density. When several reports occurred within both of those arbitrary criteria for time and space separation, by SPC criteria, they would be considered as different reports of the same event, and only one report would be retained in the record, typically the most severe. More recently, however, these SPC criteria are no longer being enforcedlocal NWS offices decide how to separate reports.

For the climatology developed in BDK03, only the so-called touchdown points for the tornadoes were used, and the finite area affected by the tornadoes was not considered in that work. Hence, the pointlike nature of nontornadic severe thunderstorm reports is, in this sense, compatible with the work reported upon in BDK03. Indeed, BDK03 and this paper constitute "companion" presentations of the total severe thunderstorm probability information in the same way that Kelly et al. (1978) and Kelly et al. (1985) constitute companion papers.

In the present paper, we will begin in section 2 with a consideration of important limitations of the raw data, including some analysis of the time and space history of the reports. In doing so, we will show a number of problems associated with inhomogeneities in the reporting of severe weather. A major issue is the secular (i.e., nonmeteorological) trend in the number of nontornadic severe thunderstorm reports, which is even more dramatic than that reported for tornadoes (Weiss and Vescio 1998). Section 3 will present the time and space distributions of nontornadic severe thunderstorm reports comparable to those presented in BDK03 for tornadoes, with modifications to account for the different characteristics of nontornadic severe weather reports. An abbreviated review of the BDK03 methodology will be included. Section 4 will present conclusions and offer some discussion concerning the application of the data and our analyses of those data.

\section{Nature of the dataset}

\section{a. Issues with reporting}

In order for a severe event to become a part of the SPC database, someone must observe that event, identify its character, and pass on that observation eventually to a NWS office, which puts it into a storm report, which then becomes part of the SPC database. The character of the event, including quantitative information about the event (wind speed and/or hailstone diameter) when available, must be included. If we ignore for the moment any questions about the accuracy of the report, it should be clear that such point reports represent only a portion of the total area affected. As mentioned in the introduction, the real events have spatial dimensions and variability both in time and space, so it would be fortuitous indeed if the observation happened to be of the absolute peak wind speed and/or the largest 


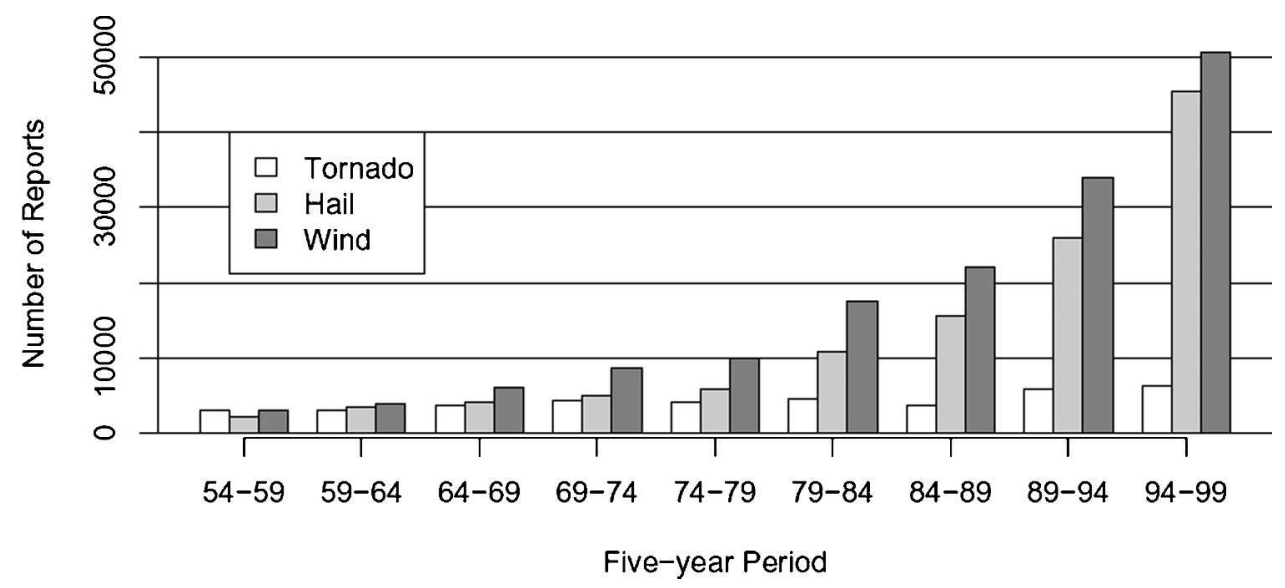

FIG. 1. The time history of the number of hail, wind, and tornado reports for the eight 5-yr periods from 1955 to 1994 . Note the apparent change in the trend beginning with the period 1979-84.

hailstone. Recent approaches to severe thunderstorm event reporting (Amburn and Wolf 1997, p. 477) make it even more likely that the largest hailstone will not be reported. Thus, it is almost certain that even if the reports were perfectly accurate, there would be a tendency for the reports to underestimate the true peak magnitude of the actual events. This could be offset partially by any tendency for observers to overestimate wind speeds and, perhaps to a lesser extent, hailstone diameters. It is also obvious that population bias will be an important factor, just as it is for tornado events. However, as we will show, the severe thunderstorm report database is rife with inhomogeneities that are not simply a reflection of the local population density or even proximity to an NWS office. Hence, attempts to correct for population bias or proximity to NWS facilities are not likely to produce a substantial improvement in the accuracy of the resulting temporal and spatial distributions. Some authors (e.g., King 1997) have noted that population bias corrections do not adequately address the problems with the data.

Of major concern is the large increase in the number of reported nontornadic severe thunderstorm events. In BDK03, it was noted that the number of reported tornadoes has increased by a factor of 2 since the mid1950s. The number of nontornadic severe thunderstorm reports has increased even more dramatically (Fig. 1). Both the hail and the wind reports have experienced more than an order of magnitude increase during the same period when tornado reports have roughly doubled.

Reasons for this growth in the number of reports are complex and have not been studied in detail, but an emphasis on improving verification of NWS severe thunderstorm warnings by enhanced efforts to seek out reports surely has been a dominant factor. This effort began in the early 1980s [and accelerated with the installation of the Weather Surveillance Radars-1988 Doppler (WSR-88Ds) and the associated modernization effort], first at only a few locations across the United States. The impact of this can be seen in Fig. 1.

Many of the measured wind speeds are associated with NWS surface observation sites with calibrated sensors. As special purpose "mesonetworks" of automated observing sites have proliferated (e.g., Brock et al. 1995), some reports of measured convective storm wind gusts are being provided by such mesonetwork sites. The calibration of these wind sensors is not generally known. Observers of severe thunderstorms also provide estimates of peak wind gust speeds, and when those estimates are available, they are entered (see Doswell 1985 for a discussion) into the database, typically without any differentiation between estimates and actual measurements. Human observers typically overestimate the wind speed, owing to a lack of experience with extreme winds.

Hailstone sizes are not typically measured, but rather are subjectively compared to various coins and other spherical objects of known size. This results in a distribution of reported hailstone diameters that is strongly "quantized" into very specific values associated with these objects of comparison. This has been discussed by Sammler (1993) and clearly is an undesirable artifact of the data. However, the impact of this effect can be minimized by reducing the number of size categories.

Within the severe storms forecasting community, there has been some informal discussion of what is or is not a "significant" nontornadic severe thunderstorm event. The current arbitrary thresholds for an event to be considered "severe" are felt by some to be too low, 
suggesting to Hales (1993), among others, that significant severe thunderstorm events are those with measured wind speeds $\geq 65 \mathrm{kt}\left(33.4 \mathrm{~m} \mathrm{~s}^{-1}\right)$ and hailstone diameters $\geq 2$ in. $(5 \mathrm{~cm})$. Although such a distinction is unofficial, we have adopted the Hales criteria for use in our analysis of the nontornadic severe thunderstorm reports. This amounts to a very simple binning of the reports into two categories (marginal and significant severe reports) that reduces some of the vagaries in the reporting, at the expense of the largely unsupportable detail. As in BDK03, we have followed a conservative approach to the problem of developing climatological occurrence probabilities, consistent with our goal to preserve primarily the features within the data that are on a scale compatible with SPC forecast products. This necessarily entails a loss of detail, but we believe that much of the detail contained in the raw data is of dubious credibility.

\section{b. Examples of spatial/temporal inhomogeneities}

A comprehensive presentation of the raw data is outside the scope of this paper. Rather, we can only provide some examples that suggest the nature of the problems with the raw data. Weiss et al. (2002) provided some similar examples with respect to the severe wind events data.

To do this, we have employed the software SVRPLOT(Hart 1993; available online at http://www.spc. noaa.gov/software/svrplot2/) to generate maps of the raw observations, summed over 5-yr periods. As a first example, consider Fig. 2. Although when considering all the wind reports, including both measured/estimated gusts and the nonquantitative "wind damage" reports, the map reveals no obvious artifact, the reports of winds between 50 and $64 \mathrm{kt}$ (inclusive) for the state of Iowa in the periods from 1985 to 1989 (not shown) and 1990 to 1994 are much more common than in surrounding states. This discrepancy is apparently due to a local policy for Iowa during some large fraction of the period 1985-94 mandating that severe convective wind reports should have a quantitative estimate of the maximum wind gust speed associated with them.

The intent of such local mandates is laudable, but they can create what amounts to anomalies in the data that might not be obvious when considering all the convective wind reports. Any careful examination of the database will reveal that changing local and national (see Galway 1989) policies regarding the severe thunderstorm reporting procedures have introduced numerous such anomalies into the data. An individual at a local NWS office can and often does have a significant impact on how the reporting of severe weather is done and, since staffing inevitably changes with time, the presence of inhomogeneities in the data is virtually guaranteed.

Thus, as a related example, the annual summaries also reveal what appear to be local policy changes. Figure 3 demonstrates a variety of obvious anomalies in the distribution of the same 50-64-kt measured/ estimated wind gust range that are changing with time: the Iowa anomaly has apparently disappeared (introducing yet another secular change in the data), whereas others have appeared starting in 1996, notably in Alabama, Georgia, part of Tennessee, part of Arkansas, part of Ohio, part of Pennsylvania, part of Illinois, and part of Kentucky. Also notable is the near absence of such reports in Virginia and West Virginia. Additional discrepancies of this sort can be noted, but the point is that considerable temporal and spatial variability is present and it seems obvious from the pattern of such changes that these discrepancies are unlikely to be meteorological in character.

As a last example, when comparing the hail reports for the period 1955-59 to those for 1980-84, it can be observed that the obvious "hole" in the reports in the Sand Hills region of north-central Nebraska (Fig. 4) was considerably reduced in the 5-yr period 1980-84 compared with virtually all other periods considered in this study. The Sand Hills region has low population density and so might naturally be expected to represent a relative minimum in severe thunderstorm reporting frequency. Just what happened in the period 1980-84 is not known and no obvious explanation is available to us.

\section{Temporal and spatial event climatology}

Our approach follows that of BDK03, in that we consider the $\log$ of reports on a daily basis and, for each day, assign the nontornadic severe thunderstorm reports to the centroid of a box on a Lambertian conic conformal grid with nominal 80-km horizontal spacing in both directions. ${ }^{2}$ The grid is true at $30^{\circ}$ and $60^{\circ} \mathrm{N}$. Grid boxes are within $5 \%$ of the same size over the entire contiguous 48 states. We consider a grid location to be "on" if one or more nontornadic severe thunderstorm event reports are present in the box and "off" if there are no reports. Thus, we have employed the same "event day" methodology as used in BDK03. Using event days is a conservative way to view the data, as it

\footnotetext{
${ }^{2} \mathrm{~A}$ grid box $80 \mathrm{~km}$ on a side encloses the same area as a circle of radius $24.6 \mathrm{n} \mathrm{mi}$, very close to the area under consideration by the SPC probability forecasts.
} 


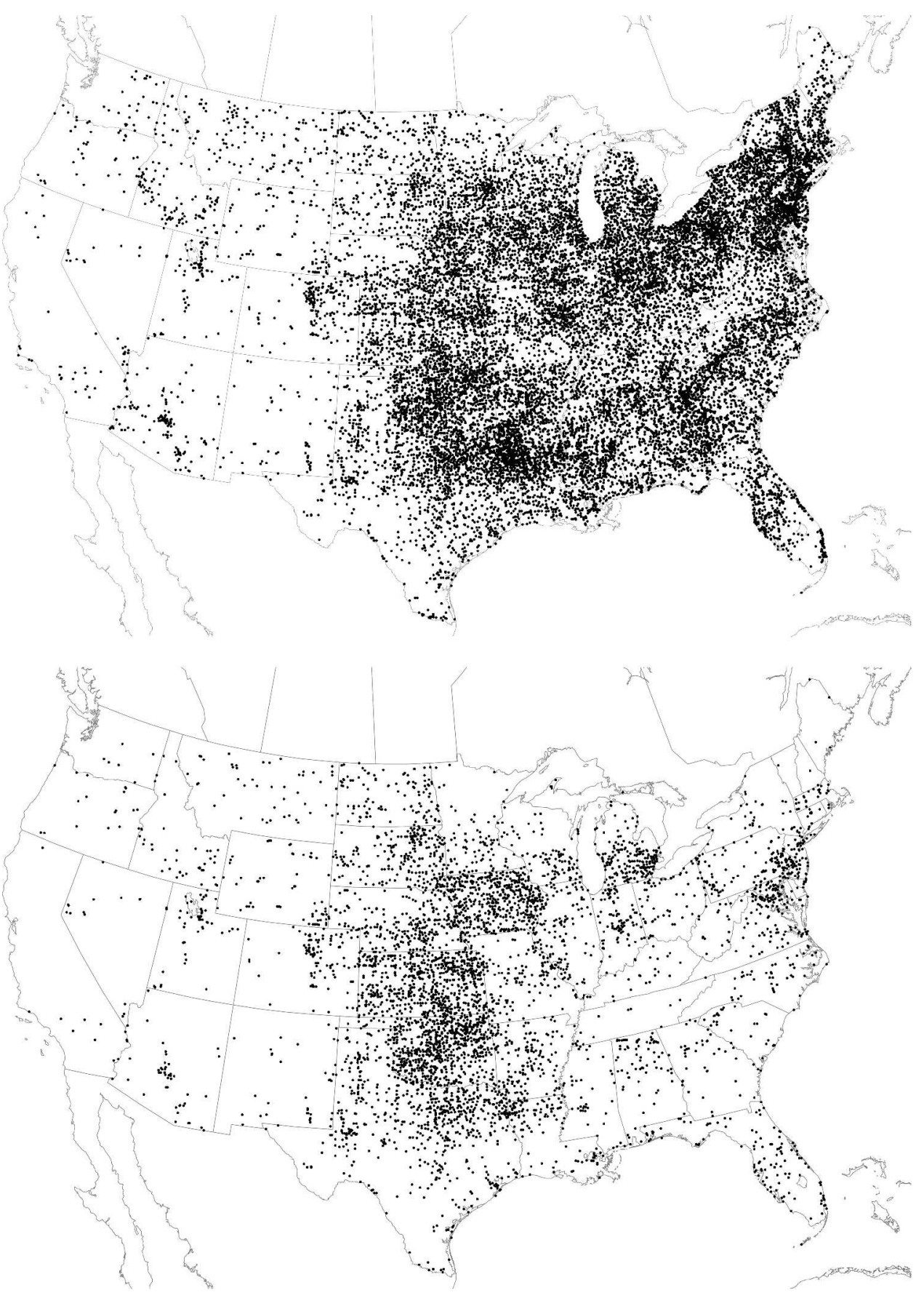

FIG. 2. (top) All severe convective wind reports, compared with (bottom) only those wind reports containing measured/estimated winds in the range 50-64 kt (inclusive), for the 5-yr period 1990-94.

is more robust than counting the number of reports-it reduces, but does not entirely remove, the impact of the large secular changes in event reporting. This dichotomous approach also makes some aspects of the analysis simpler: the primary final product of this method is the frequency (probability) of an event at any point on the grid on any day of the year. From that product, we have created maps of threat for any time period during the calendar year, and we have graphed the annual cycle of threat at any point. (All of these maps and graphs can be found online at http://www.nssl.noaa.gov/hazard/.)

The procedure followed, as described in BDK03, involves the use of nonparametric density estimation (Silverman 1986). As discussed earlier, by using the event 


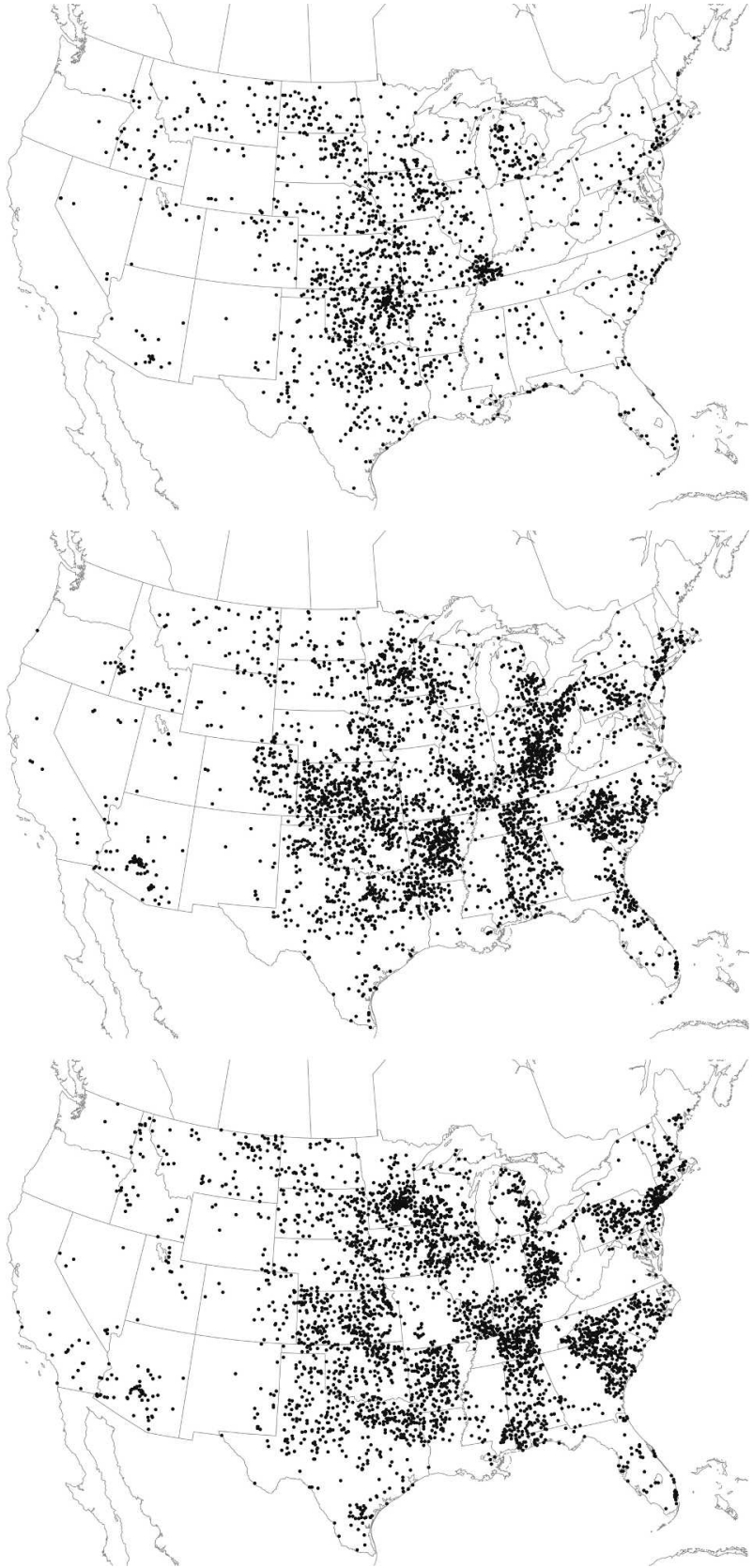

FIG. 3. Distribution of measured/estimated convective wind gusts in the range 50-64 kt, for (top) 1995, (middle) 1996, and (bottom) 1997.

day methodology, the value of $m$ for a grid box on any day within a given year is either 0 or 1 . For multiyear periods, the average value of $m$ has a range between 0 and 1 and represents an average probability for that period of choice. Then a temporal smoothing is done using a Gaussian kernel described by

$$
f_{n}=\sum_{k=1}^{366} \frac{m}{\sqrt{2 \pi} \sigma_{t}} \exp \left[-\frac{1}{2}\left(\frac{n-k}{\sigma_{t}}\right)^{2}\right]
$$

where $f_{n}$ is the value for the $n$th day of the year, $k$ is an index for the day of the year, and $\sigma$ is the so-called smoothing parameter for the temporal dimension. The data record is treated as periodic to avoid problems with dates near the beginning and end of the year.

Following the temporal smoothing, a spatial smoothing with a Gaussian kernel is performed according to

$$
p_{x, y, n}=\sum_{j=1}^{J} \sum_{i=1}^{\mathrm{I}} \frac{f_{n}}{2 \pi \sigma_{x}^{2}} \exp \left[-\frac{1}{2}\left(\frac{d_{i, j}}{\sigma_{x}}\right)^{2}\right],
$$

where $p_{x, y, n}$ is the mean expected number of event days for that particular event criterion per year or, equivalently, the probability of an event meeting the chosen criteria being reported in the grid box at location $(x, y)$ on day $n ; d_{i, j}$ is the Euclidean distance between analysis location $(x, y)$ and the data location $(i, j)$; and $\sigma_{\mathrm{x}}$ is the spatial smoothing parameter. In addition, $I$ and $J$ are the numbers of grid points in the east-west and northsouth directions on the grid, respectively. Subjective review of the results using various smoothing parameters led BDK03 (see 628-629) to choose $\sigma_{t}=15$ days and $\sigma_{x}=120 \mathrm{~km}$ (1.5 grid points), in an effort to provide patterns consistent with SPC Convective Outlook products. We have used the same values so that the smoothing of the nontornadic severe thunderstorm reports is the same as that of the tornado reports. Figure 5 compares the resulting smoothed patterns averaged over the 5-yr period 1990-94, chosen simply as an example, with the distribution of the raw reports of hail during the same period. Many of the details are smoothed out and the resulting pattern should be viewed as a conservative depiction of the distribution of hail reports, retaining only the broad patterns and suppressing unsupportable detail. Figure 6 provides the same comparison for all of the wind reports during the same period. As suggested in BDK03, care must be exercised in the interpretation of details near the edges of the United States territory. Since we have no data outside of the 48 contiguous states, the smoothing naturally creates an underestimate of the probability along the national boundaries.

\section{a. Total threat}

As suggested by Figs. 5 and 6, the average distributions of nontornadic severe thunderstorms are rather complex. The period of record, 1955-99, has been divided into 5-yr subperiods, as was done in BDK03. Given the enormous secular trends in the data (cf. Fig. 1 ), the apparent frequency of severe weather has changed and it is obvious that this would be reflected in 


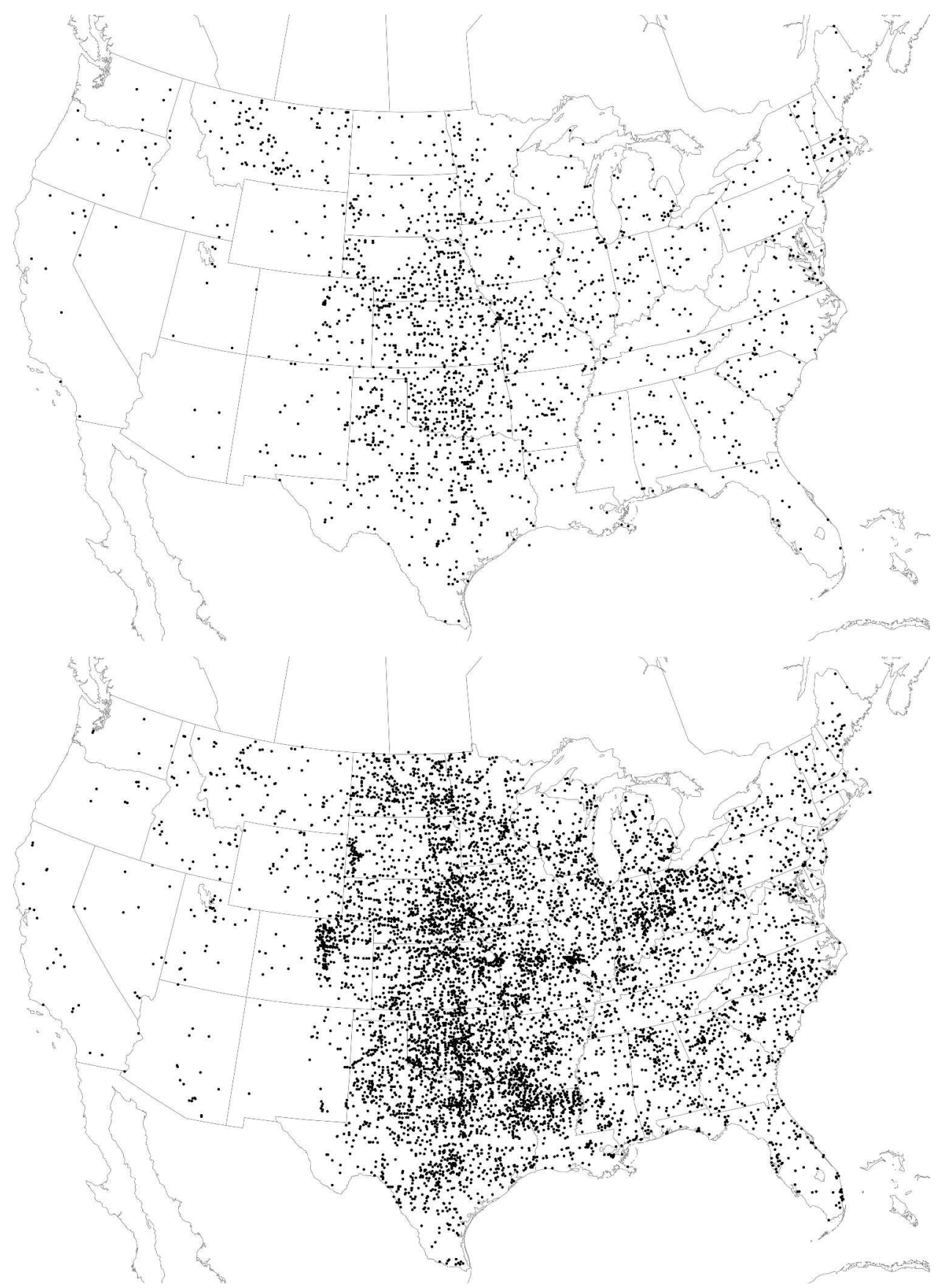

FIG. 4. (top) All severe hail reports for the period 1955-59, compared with (bottom) all severe hail reports for the period $1980-84$.

a substantial increase in the calculated frequency. However, it should be noted that at least some of the trend has been mitigated by the method we have employed, which offsets the increase in the number of reports to some extent, since we consider only whether or not at least one report is within a grid box on a given day. Note that the daily probabilities have roughly doubled during the period, whereas the number of reports has increased by a factor of 5-10 over that time period. Nevertheless, some of the huge increase in reporting frequency remains in our smoothed probability maps, as shown in Figs. 7 and 8. As noted in BDK03, we do not have the luxury of a long, stable record of observations. In fact, as we have indicated in section 2 , the 


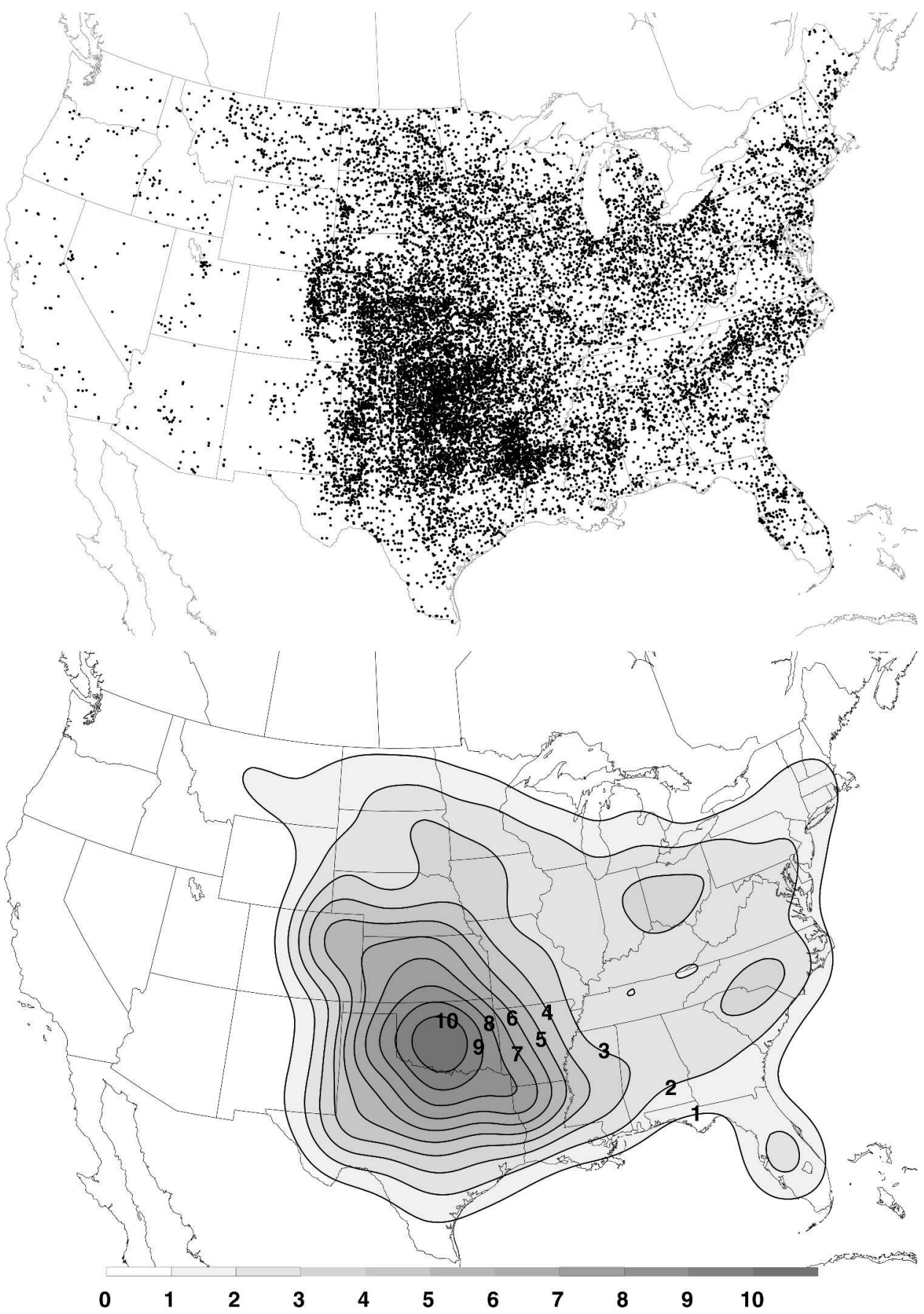

FIG. 5. Comparison of (top) the raw severe hail reports of any size with (bottom) the smoothed annual probability using the kernel density estimation technique described in the text. Probability contour values are in percent, starting at $1.0 \%$.

observations are far from stable and contain many secular artifacts.

\section{b. Significant severe thunderstorm events}

Considering only events that are deemed significant nontornadic severe thunderstorm reports, the smoothed distributions for the extended period 198094 and the raw reports are compared for hail $\geq 2$ in. in diameter (Fig. 9) and for measured/estimated wind gusts $\geq 65 \mathrm{kt}$ (Fig. 10). The patterns reveal an apparent preference for significant severe events in the Great Plains, with a hint of a secondary axis into the Ohio 


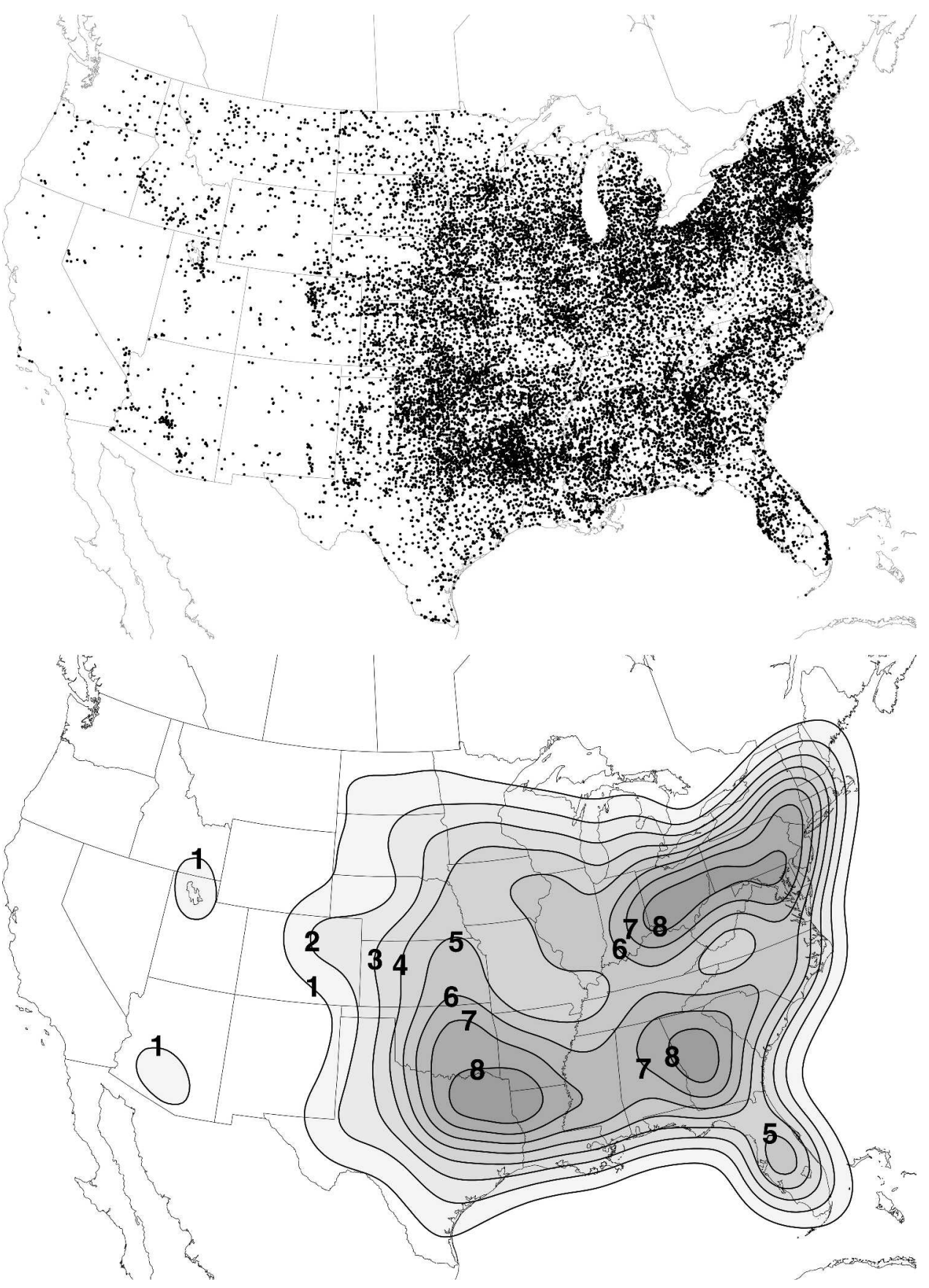

FIG. 6. As in Fig. 5 except for all severe convective wind reports.

Valley. The significant wind gust reports show a greater tendency for the Ohio Valley axis than do the significant hail reports.

Although we have no reason to believe that significant severe thunderstorm reports are completely immune to the temporal and spatial inhomogeneities we have demonstrated are present in the general record of nontornadic severe thunderstorm reports, the history of their growth is considerably more conservative than that for reports near the arbitrary threshold for being deemed as severe (Fig. 11), a point also made by Weiss et al. (2002). Inflation of the significant nontornadic severe thunderstorm reports becomes evident in the 5-yr period 1990-94 and may have begun in the period 1980-84, when the trend began for all nontornadic severe thunderstorm reports, but had not yet attained an 


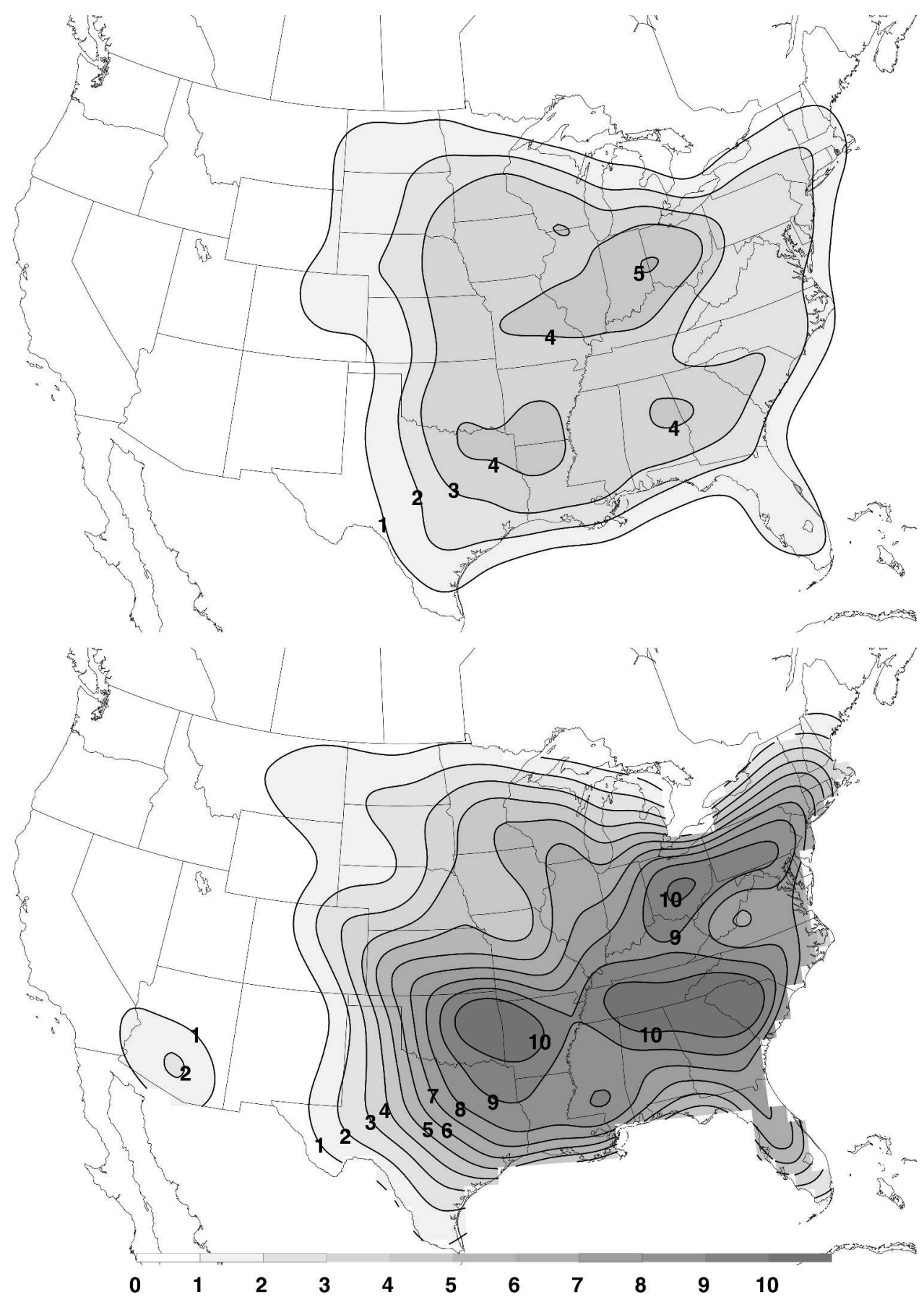

FIG. 7. Comparison of the smoothed frequency (per day) of any severe convective wind event for (top) the period 1980-84 and (bottom) 1995-99. Contours are probabilty, in percent, starting at 1.0\%.

increase as large as a full order of magnitude by the end of 1999. The inclusion of "significant" tornadoes in this figure is, for comparison purposes, comparable to Fig. 1. As discussed by Grazulis (1993) and Brooks and Craven (2002), there may have been some overestimation of the $\mathrm{F}$ scale associated with reports in the 1950s through the mid-1970s and so the apparent decrease in the frequency of significant tornadoes may be an artifact, as well.

\section{c. Annual cycle}

The annual cycle of nontornadic severe thunderstorms is broadly similar to that for tornadoes (see Fig. 


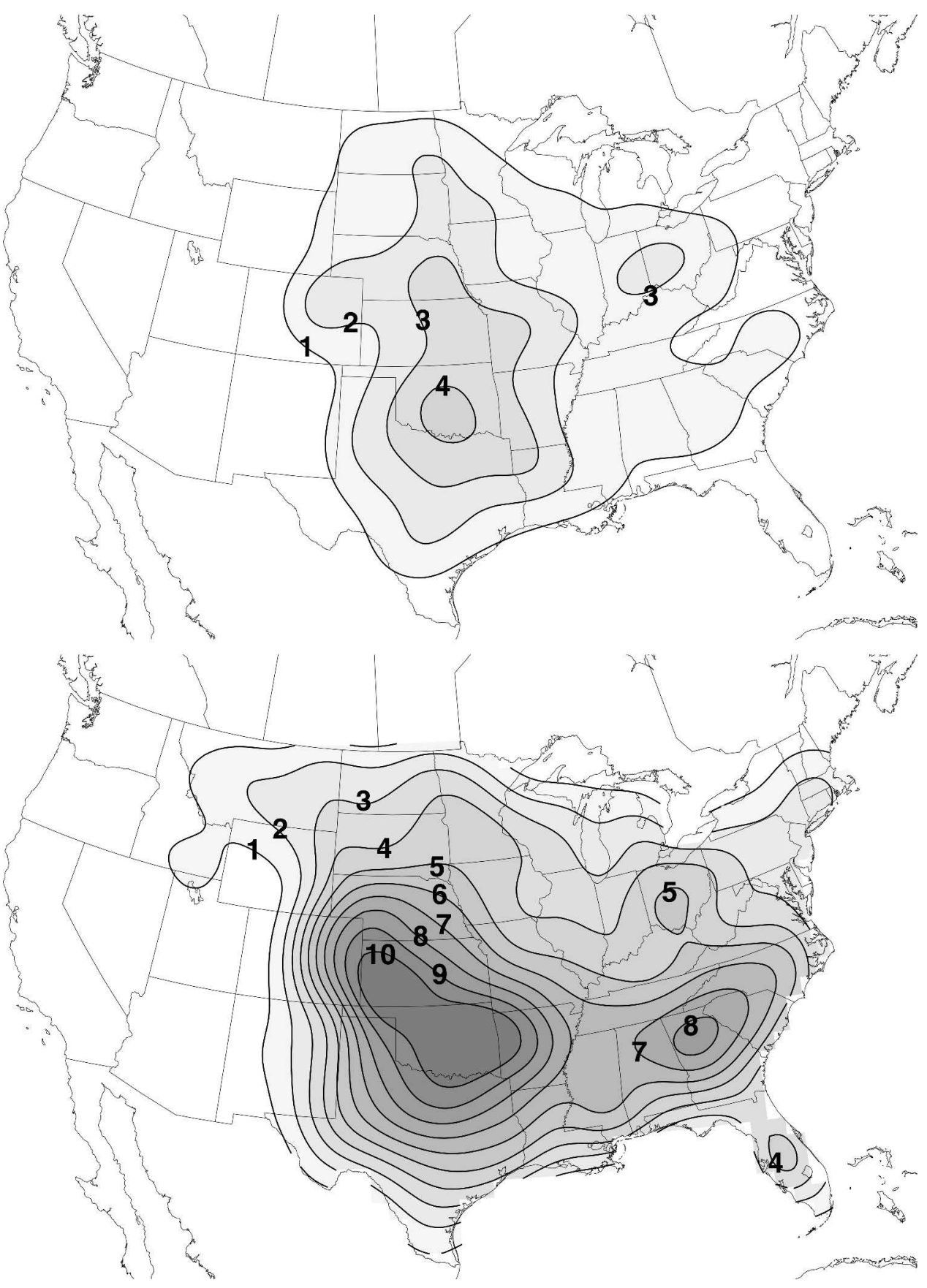

FIG. 8. As in Fig. 7 but for any severe hail.

7 in BDK03). Generally, events begin the year in the region bordering the western Gulf of Mexico and spread both eastward across the Deep South and westward into the southern plains. The peak frequencies generally lie over the southern plains in late spring, and as the overall frequency declines, the location of the maximum frequency shifts northward and eastward into the summer. In the fall, the frequencies have fallen considerably and by late fall, the residual occurrences have migrated southward back toward the southern plains and the Gulf coast.

There are some variations from this pattern, depending on the specific forms of the nontornadic severe events. For example, Fig. 12 reveals that there are two late spring/early summer peaks in severe hail of any size: one in a region from northeastern Georgia across 


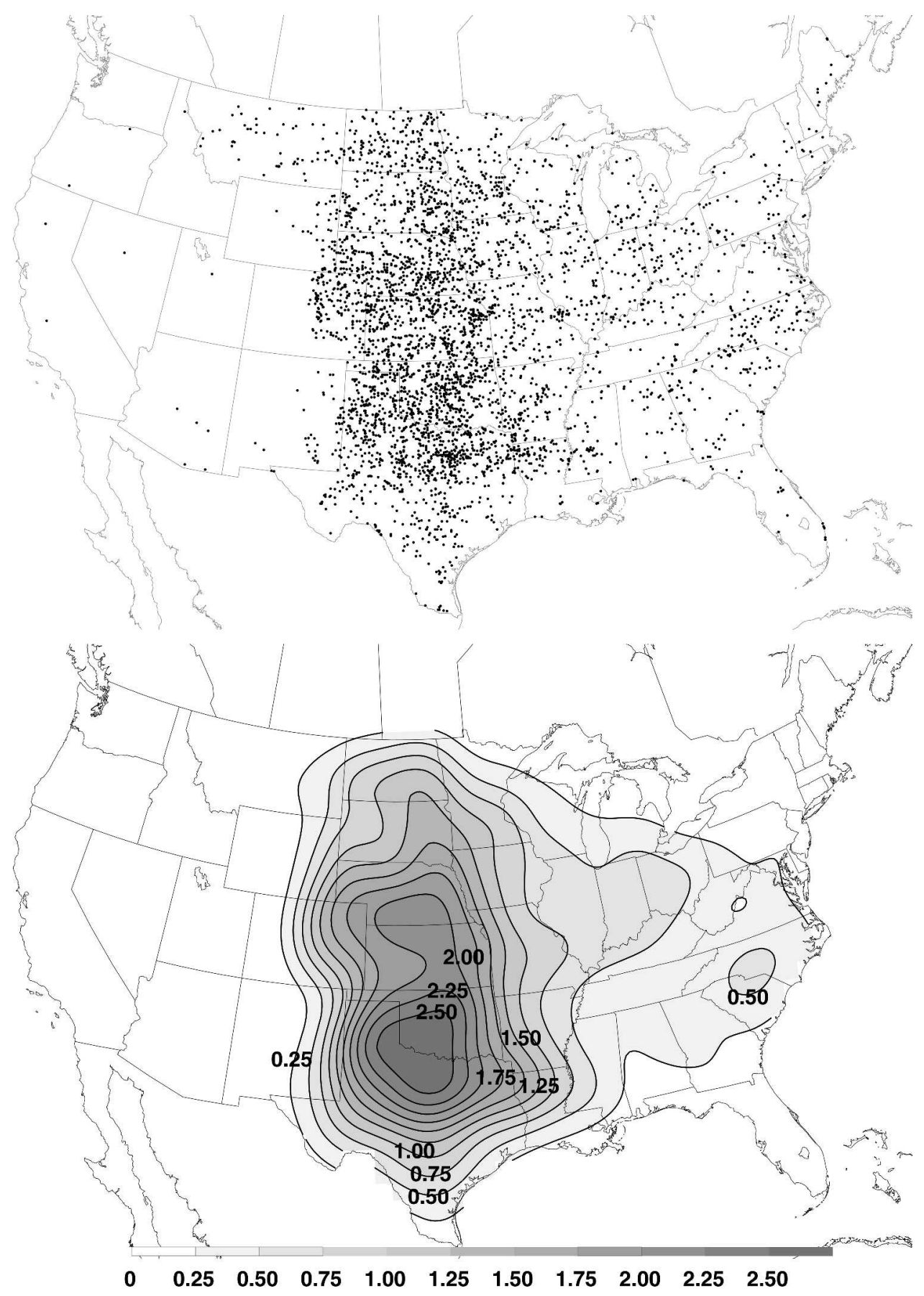

FIG. 9. As in Fig. 5 except for all hail reports $\geq 2$ in. in diameter for the period 1980-94; contour values are in percent, starting at $0.25 \%$.

the Carolinas, and another in eastern Indiana and Ohio. In spite of this exception, severe hail is predominantly an event of the southern and central plains, east of the Continental Divide and west of the Mississippi River.

In contrast to this is the annual progression of severe convective wind events of any sort (Fig. 13). Noteworthy are the late spring/early summer peaks across the Ohio Valley and in the same region of northeastern Georgia across the Carolinas noted above. For wind events of any kind meeting the severe criteria described in section 1 , the highest frequencies are east of the 


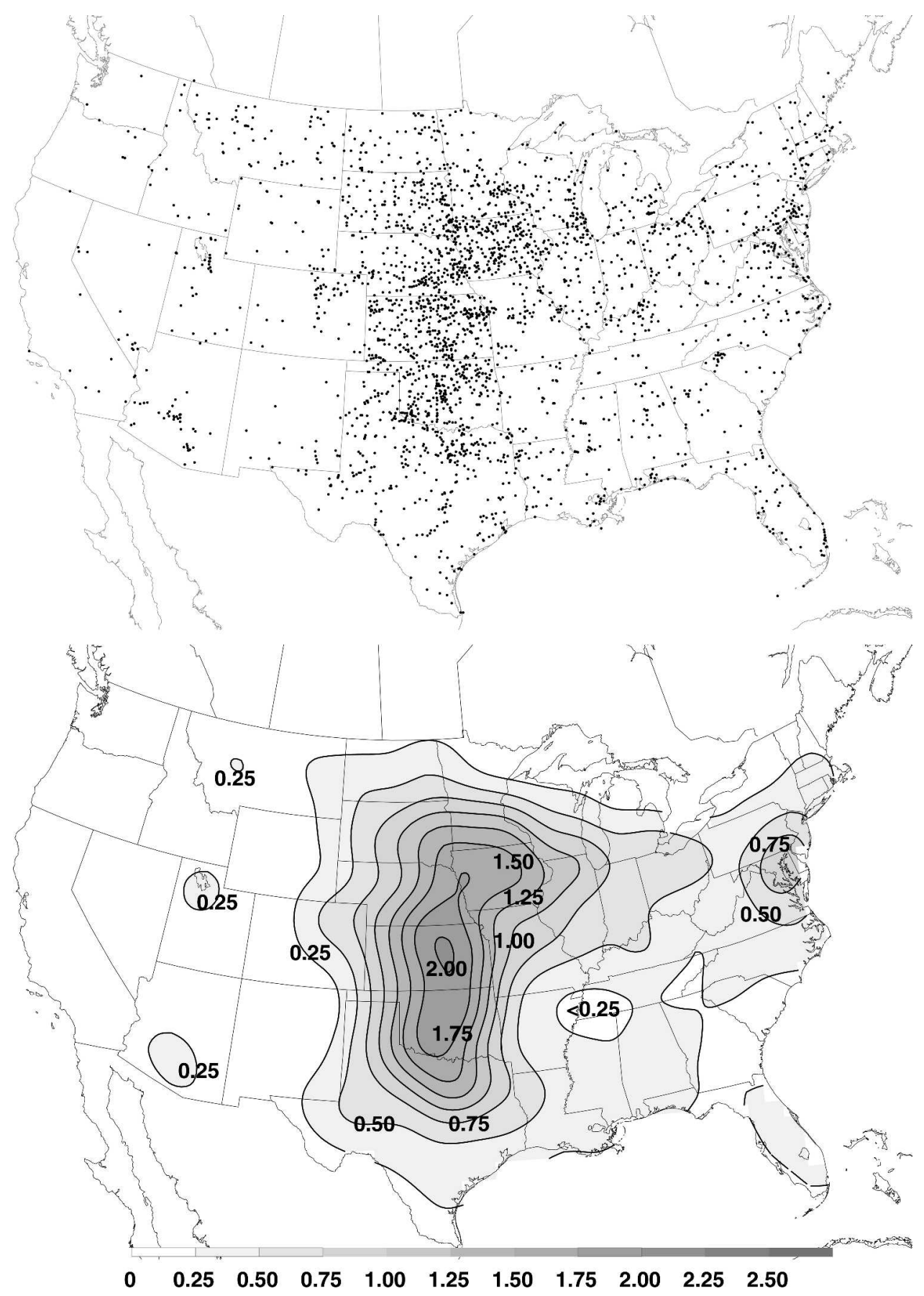

FIG. 10. As in Fig. 9 except for all convective wind reports $\geq 65$ kt.

Mississippi River for a substantial part of the warm season.

The occurrence frequencies of significant severe hail (Fig. 14) most closely fit the general picture described at the beginning of this section: starting in the Deep South and migrating northward from the southern plains to the central plains and on to the northern plains through the warm season, with a rapid fall in frequencies as the summer wanes and the peak frequencies return southward. There are modest peaks in late spring/early summer in the Ohio Valley and the Carolinas again, but when considering only the significant severe hail events, these peaks are not as pronounced as they are in all severe hail events. 


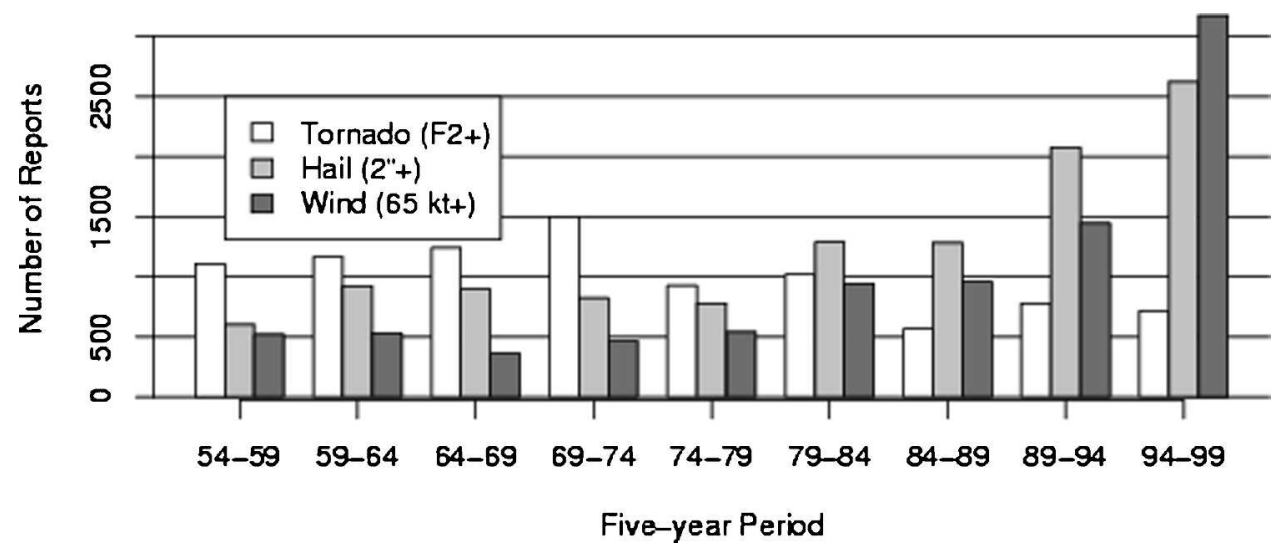

FIG. 11. As in Fig. 1 except for significant severe thunderstorm reports (winds $\geq 65$ kt, hail $\geq 2$ in., and tornadoes rated $\geq \mathrm{F} 2$ ).

Finally, the significant wind events (Fig. 15) reveal a somewhat different pattern: apart from the northward shift of such events from the southern plains to the northern plains through the spring and on into summer, an axis of relatively high frequency can be seen extending from the northern plains across the Ohio Valley by the summer. This is broadly similar to the comparable frequency maps in BDK03 (their Fig. 7). Again, a relatively weak peak in frequency shows up over the Carolinas.

\section{Discussion and conclusions}

It has been shown that the record of nontornadic severe thunderstorm reports is spatially and temporally nonhomogeneous, and it continues to evolve. Users of the data are cautioned to be aware of these problems, and to recognize that no simple method based, for example, on population density or proximity to a radar (e.g., Ray et al. 2003) is going to do much to address the existing problems with the data. We have shown that local decisions about the reporting of severe thunderstorms, whatever might motivate them, are simply introducing more deleterious inhomogeneities into the data. To a limited extent, the effect of the reporting vagaries we have shown can be reduced but not removed from any analysis of the existing SPC data. A reporting system for severe thunderstorm events needs to be developed and applied uniformly and consistently around the nation if we are ever to develop a reasonably detailed record of severe weather. Other nations also have a need for such a reporting system-the United States should take a leadership role in committing to an improved severe storm reporting system.

In this paper as well as in BDK03, we have developed and demonstrated a methodology that can compensate partially for the inhomogeneities, but they are by no means removed from our maps of climatological frequency. When and if a systematic way to record severe thunderstorm events is designed and implemented, it will take decades of consistent data collection for a statistically sound picture to emerge. Perhaps then it might be possible to do a retrospective look at the data we now have and attempt to produce an extended climatology for nontornadic severe weather by detrending the data we currently have. As it is, our perception of the probability of nontornadic severe thunderstorm events surely still contains secular (nonmeteorological) trends.

This clearly has important implications for any attempt to deduce national and regional climate change from these observations. Furthermore, it complicates the task of forecasting when the observed climatology contains inhomogeneities and trends that clearly are nonmeteorological. In spite of all these drawbacks, our analysis of the data implies certain plausible hypotheses about the processes that produce severe weather. Hail events are predominantly associated with the Great Plains in the warm season, and this is especially so for significant hail events ( $\geq 2$ in. in diameter, $d$ ). Recently, the distribution of reports of marginal hail events ( $3 / 4$ in. $\leq d<2$ in.) has become more widespread, but significant hail events are still mostly confined to the Great Plains. This suggests that most hail events with $d \geq 2 \mathrm{in}$. are associated with supercells, as has been suggested by others (e.g., Rasmussen and Blanchard 1998; Thompson et al. 2003).

Convective wind events of any magnitude are more widely distributed east of the Continental Divide than are hail events of any magnitude, but again the significant events, with peak gusts $\geq 65 \mathrm{kt}$, are mostly confined to the plains. It appears that supercells may be responsible for a large fraction of such wind events as well, although the existence of an axis of significant 
(a)
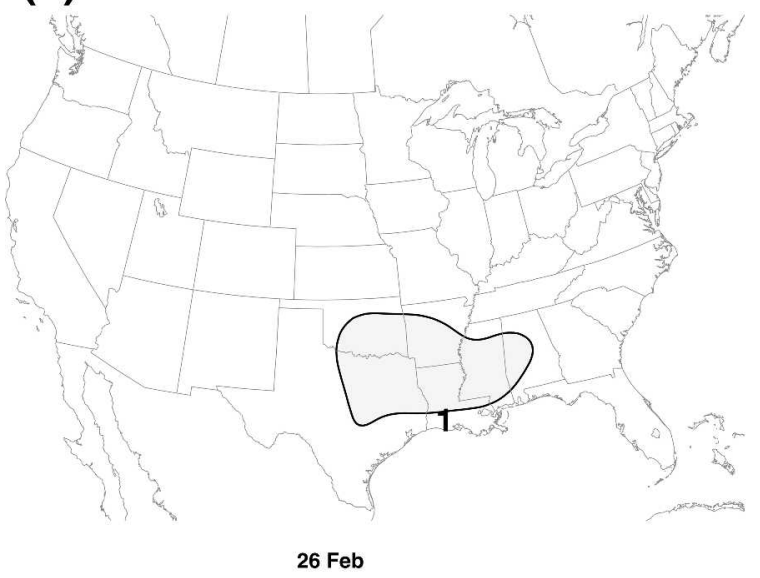

(c)

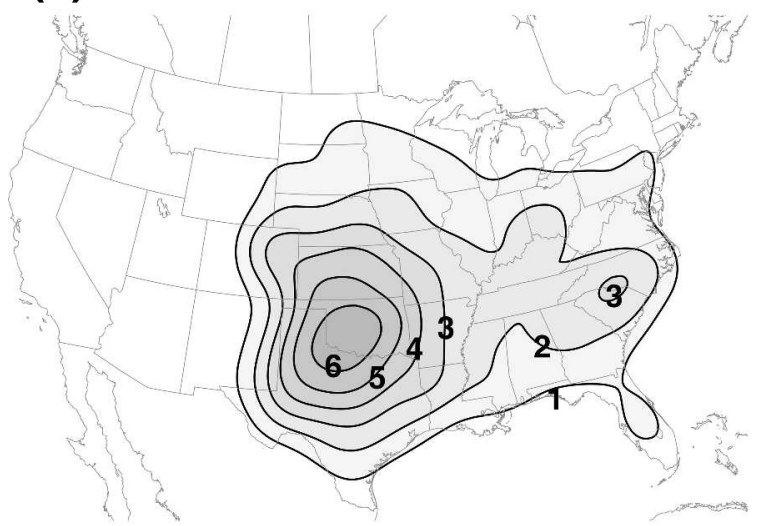

(e)

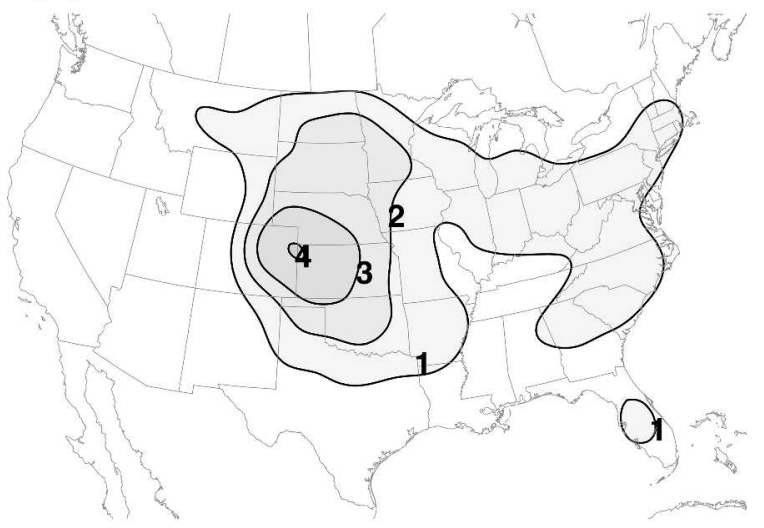

15 Jul (b)

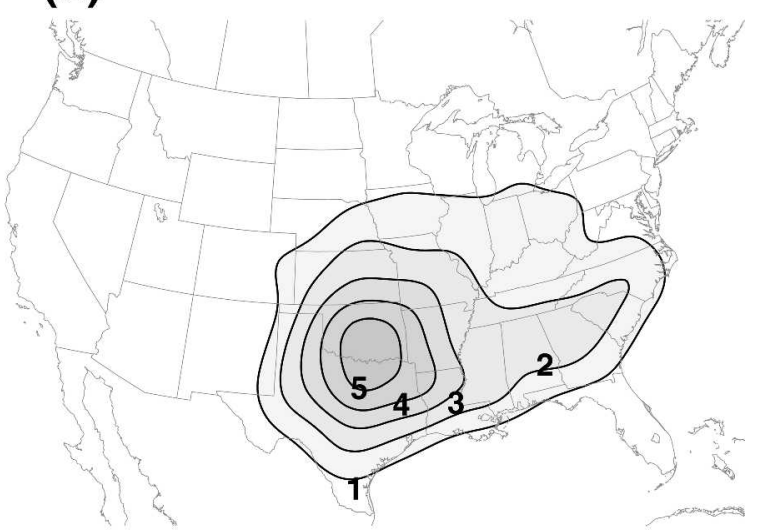

$22 \mathrm{Apr}$

(d)

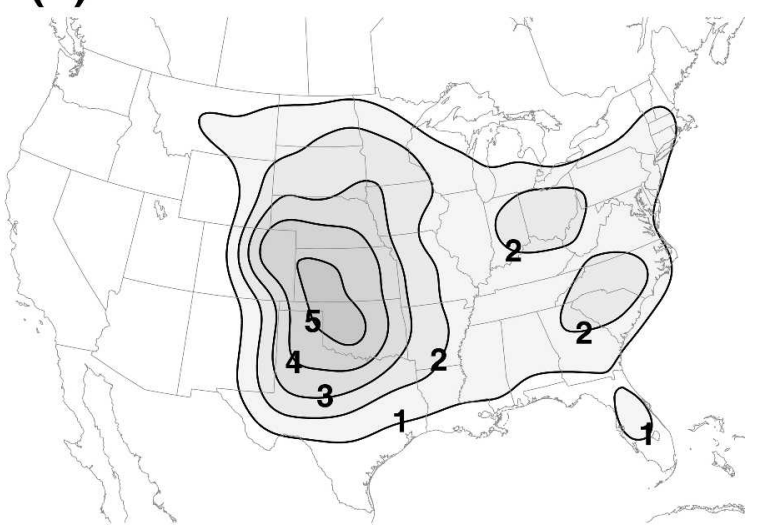

(f)

17 Jun

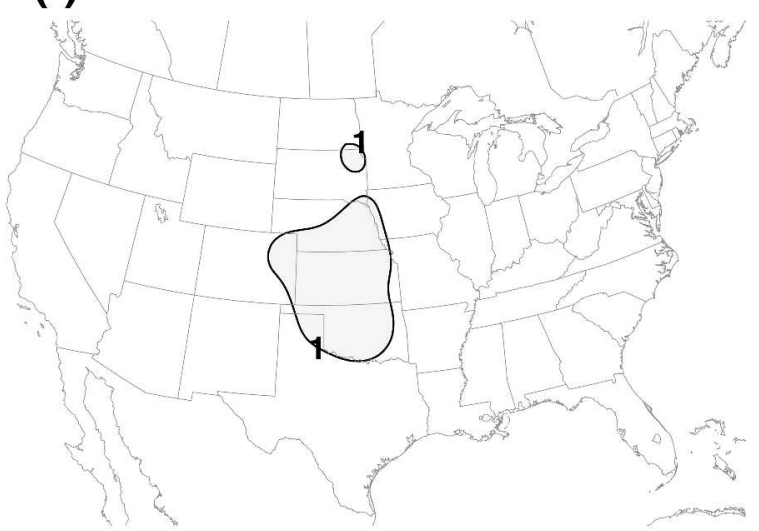

09 Sep

\section{$\begin{array}{lllllllllll}0 & 1 & 2 & 3 & 4 & 5 & 6 & 7 & 8 & 9 & 10\end{array}$}

FIG. 12. Selected maps of the smoothed (using the kernel density estimation technique) probability of severe hail ( $\geq 3 / 4$ in. diameter) for the indicated day of the year: (a) 26 Feb, (b) 22 Apr, (c) 20 May, (d) 17 Jun, (e) 15 Jul, and (f) 9 Sep. Probability contour values are in percent, starting with $1.0 \%$. 
(a)

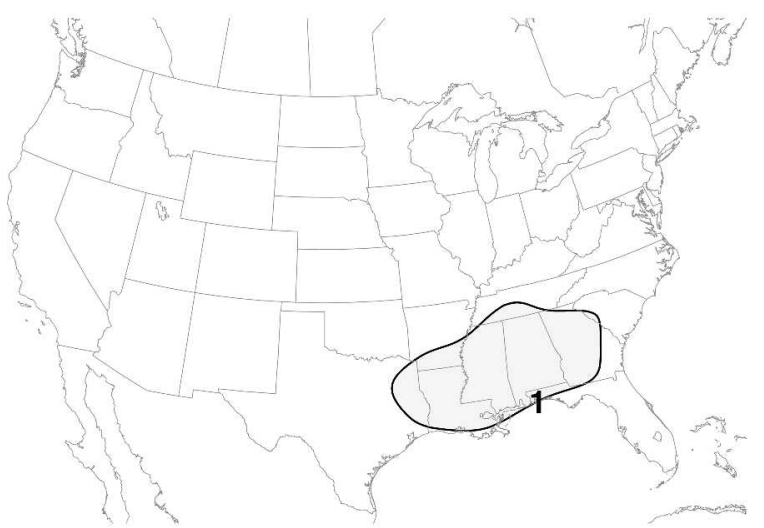

(c)

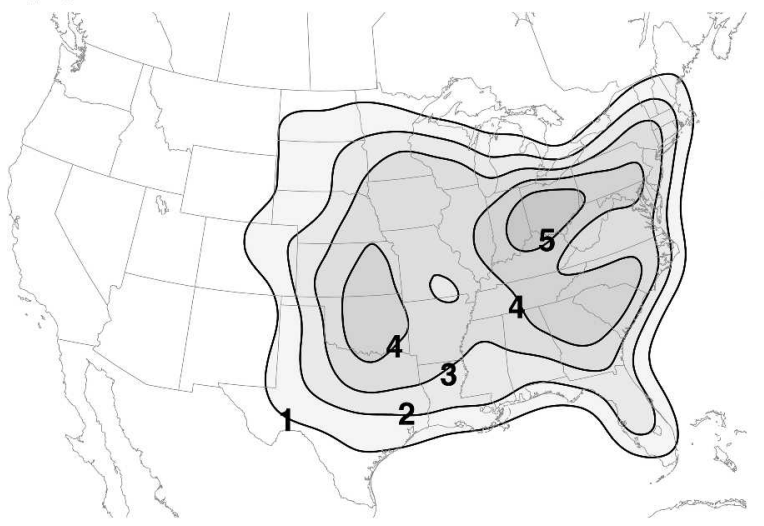

(e)

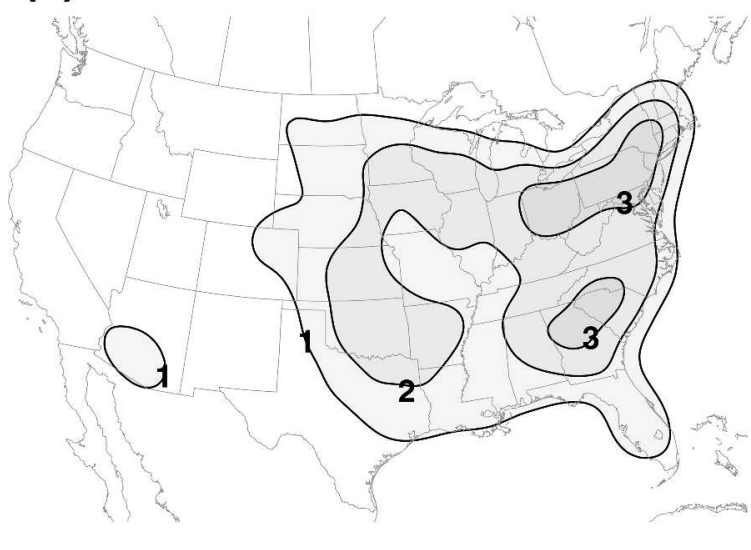

12 Aug (b)

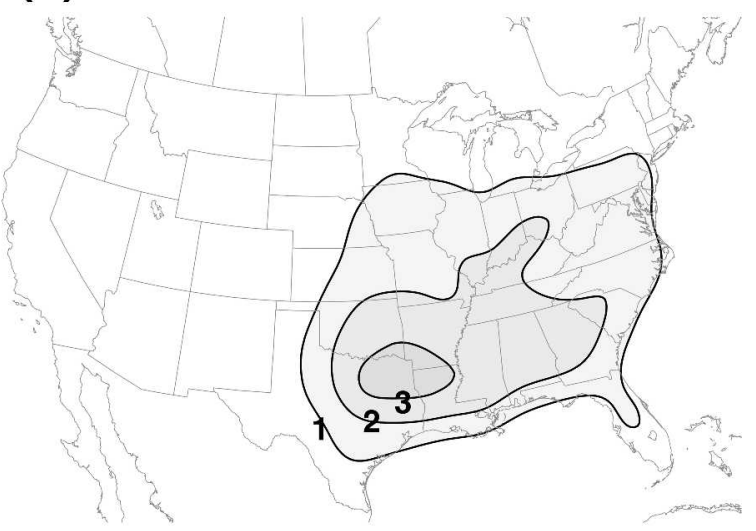

(d)

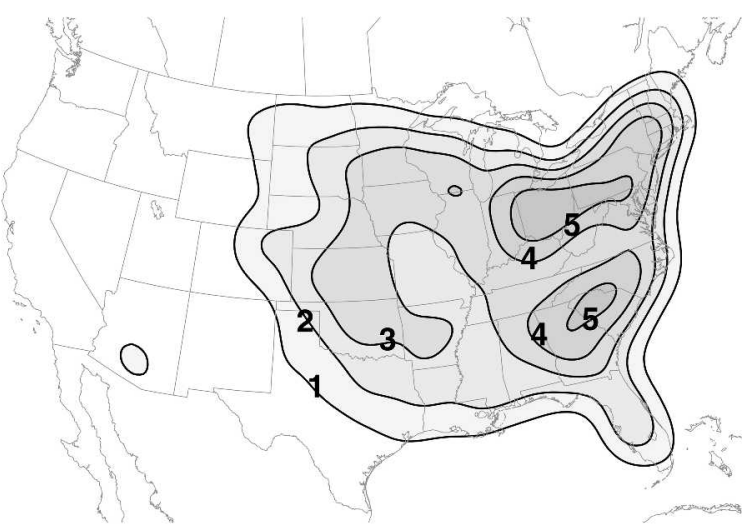

(f)

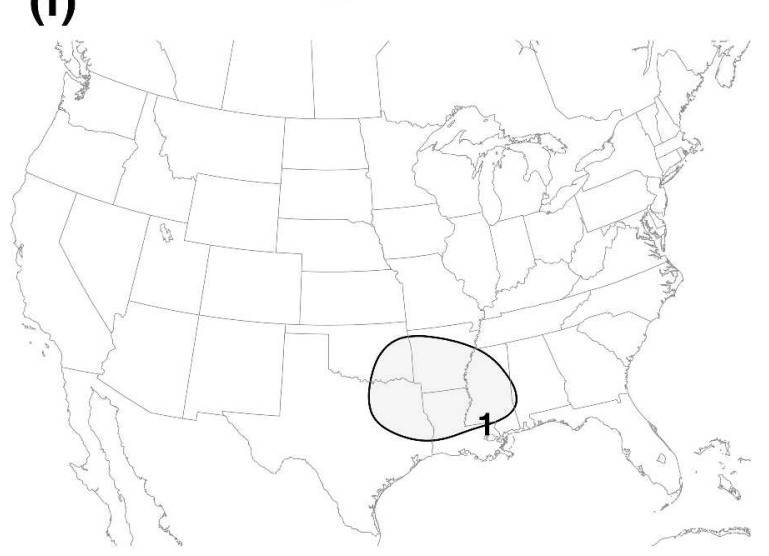

04 Nov

\section{$\begin{array}{lllllllllll}0 & 1 & 2 & 3 & 4 & 5 & 6 & 7 & 8 & 9 & 10\end{array}$}

FIG. 13. As in Fig. 12 except for the probability of severe wind gusts ( $\geq 50 \mathrm{kt}$ or wind damage): (a) 26 Feb, (b) 22 Apr, (c) 17 Jun, (d) 15 Jul, (e) 12 Aug, and (f) 4 Nov. 
(a)

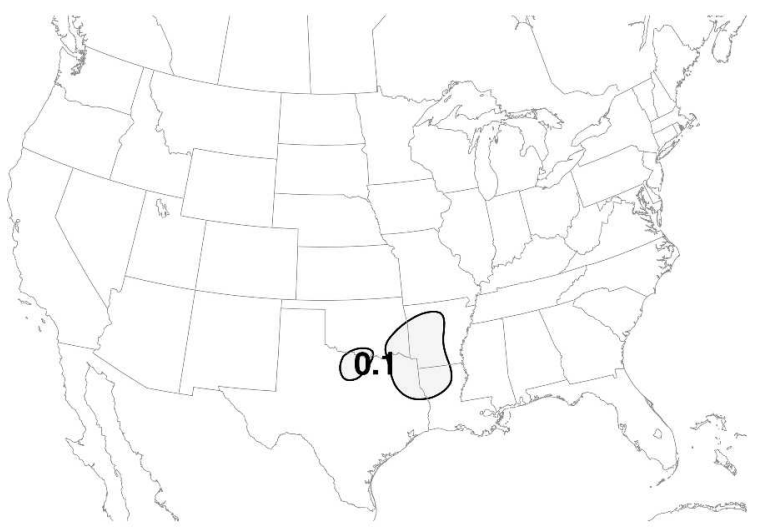

(c)

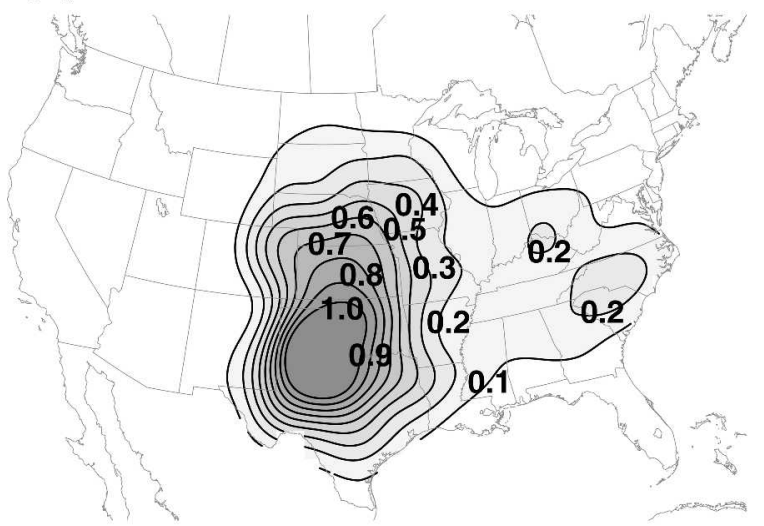

(e)

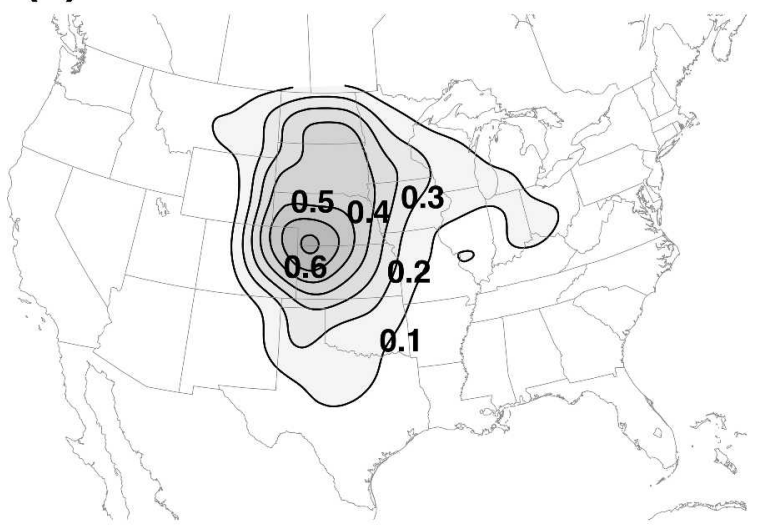

$15 \mathrm{Jul}$ (b)

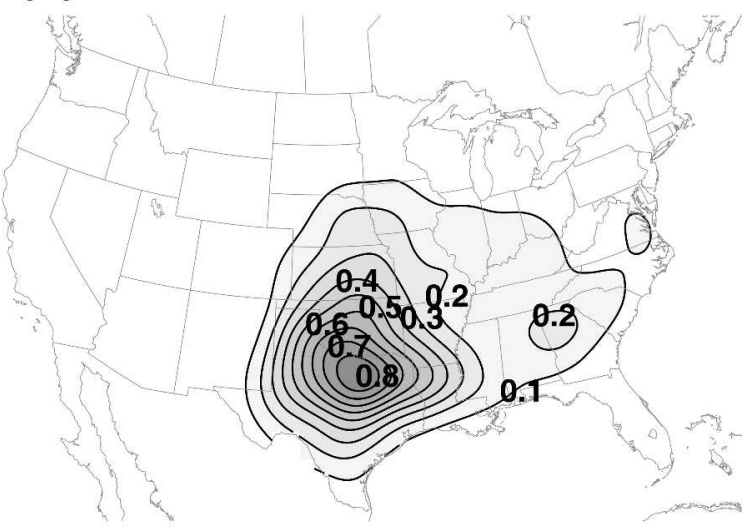

(d)

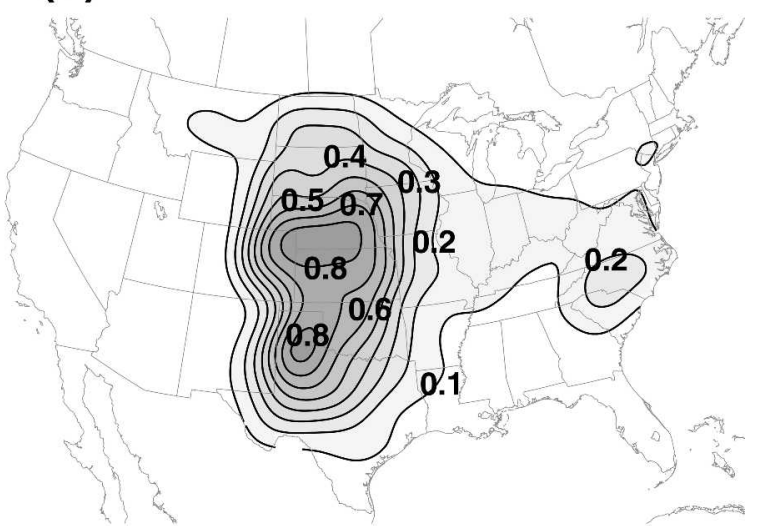

(f)

17 Jun

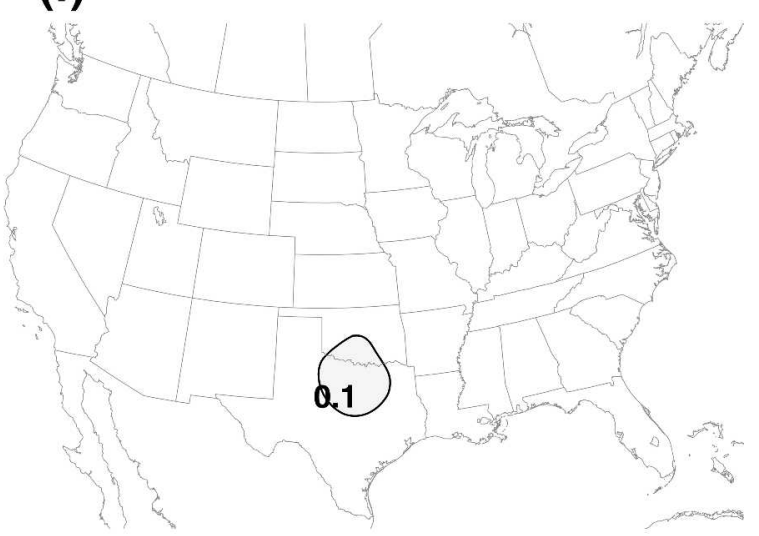

07 Oct

\section{$\begin{array}{lllllllllll}0.0 & 0.1 & 0.2 & 0.3 & 0.4 & 0.5 & 0.6 & 0.7 & 0.8 & 0.9 & 1.0\end{array}$}

FIG. 14. As in Fig. 12 except for significant severe hail ( $\geq 2$ in. diameter): (a) 26 Feb, (b) 22 Apr, (c) 20 May, (d) 17 Jun, (e) 15 $\mathrm{Jul}$, and (f) 7 Oct. The contour interval is $0.1 \%$, and the lowest contour value is 0.1 . 
(a)

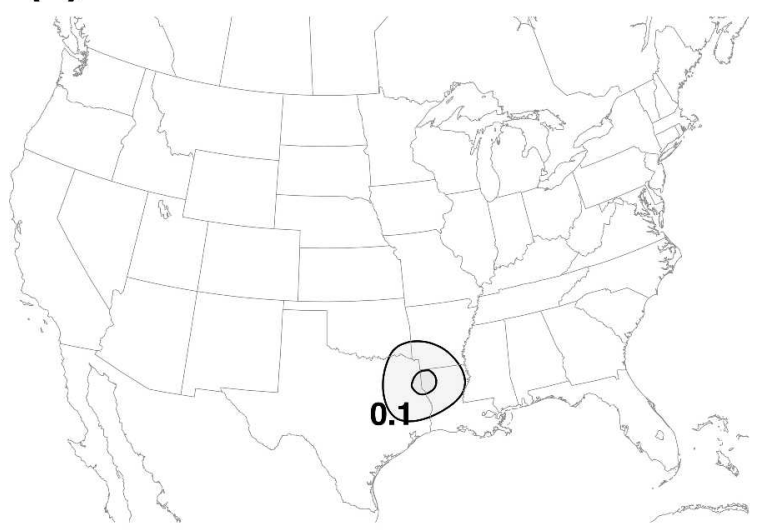

(c)

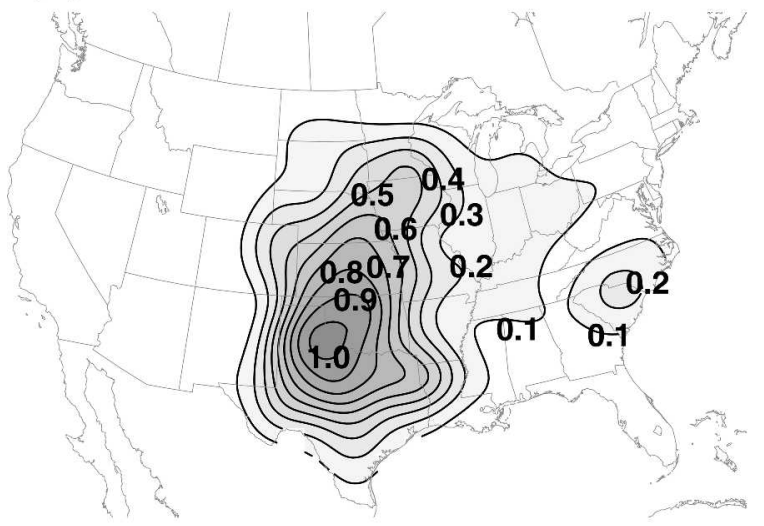

(e)

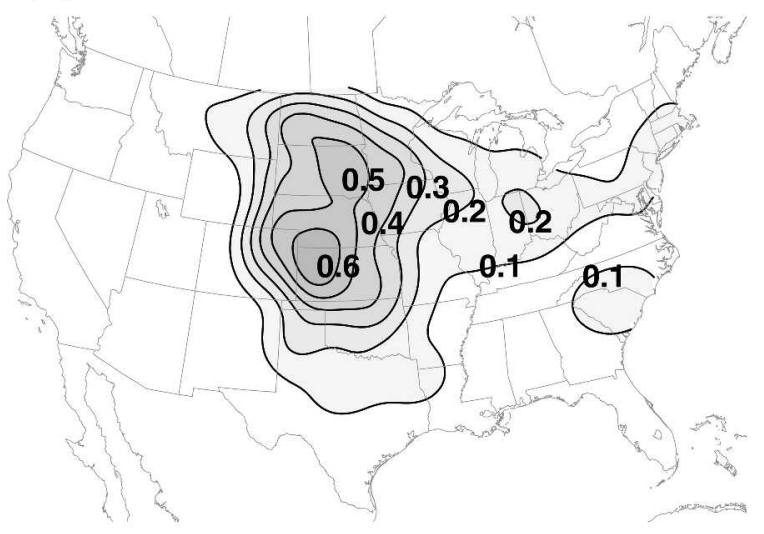

$15 \mathrm{Jul}$ (b)

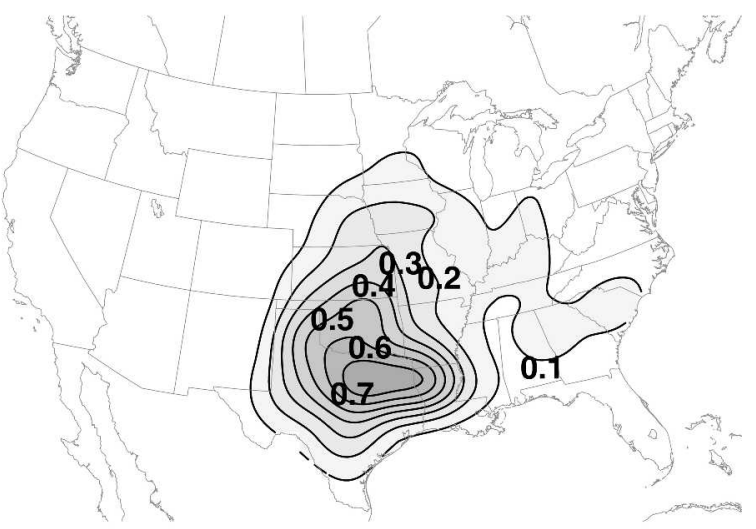

(d)

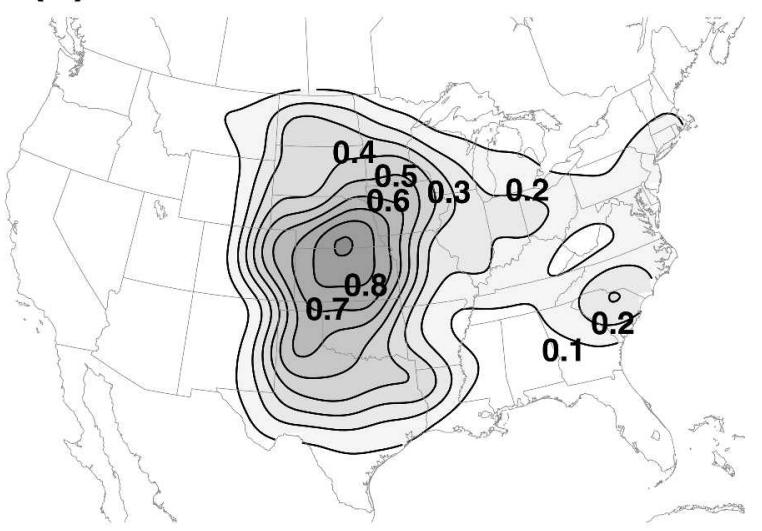

(f)

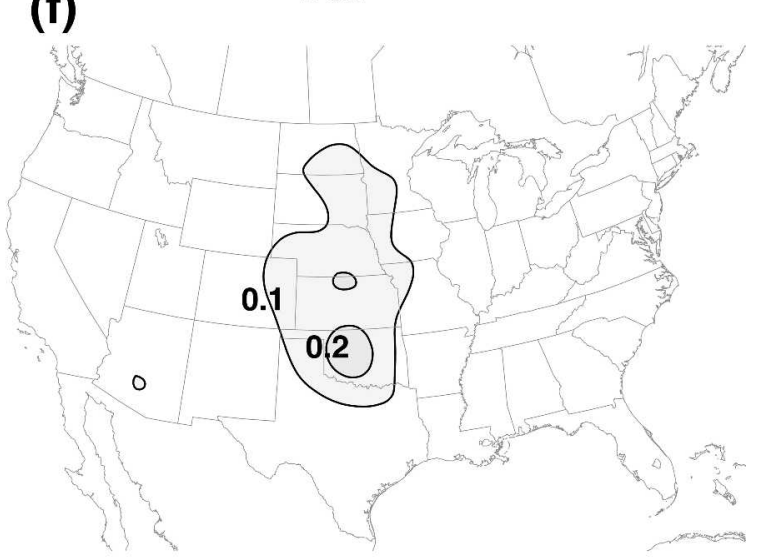

09 Sep

\section{$\begin{array}{lllllllllll}0.0 & 0.1 & 0.2 & 0.3 & 0.4 & 0.5 & 0.6 & 0.7 & 0.8 & 0.9 & 1.0\end{array}$}

FIG. 15. As in Fig. 14 except for significant wind gusts ( $\geq 65$ kt): (a) 26 Feb, (b) 22 Apr, (c) 20 May, (d) 17 Jun, (e) 15 Jul, and (f) 9 Sep. 
wind events (and tornadoes) across the northern plains into the Ohio Valley may be associated mostly with nonsupercellular derecho events in the warm season, first described by Johns and Hirt (1987), and recently discussed by Coniglio and Stensrud (2004).

Although we are not specifically concerned with tornadoes here, it is noteworthy that significant tornadoes (those rated F2 and higher on the Fujita scale) show a less pronounced tendency for being confined to the Great Plains than do significant wind and hail events [cf. our Figs. 9 and 10 to Fig. 1 in Concannon et al. (2000) or with the figure available online at http:// www.nssl.noaa.gov/users/brooks/public/sigt2195.gif]. The presence of significant tornado events east of the Mississippi could be associated with the anecdotal observation that early spring supercells, especially in the so-called Dixie Tornado Alley mentioned by Kelly et al. (1978), seem much less likely to produce significant convective winds and hail than their counterparts occurring later in the season (which are likely to be responsible for the significant warm season nontornadic events over the Great Plains). That our analysis of the data seems to be consistent with such interpretations provides some limited assurance that our conservative approach to developing climatological probabilities based on the existing database is at least providing plausible results. Although there can be no substitute for accurate, high-resolution observations, by being conservative in our methodology, we believe that the resulting patterns are qualitatively, if not quantitatively, accurate. Given the problems we have shown concerning the data, it is encouraging that some meteorologically reasonable signals are revealed by careful smoothing of the data.

Acknowledgments. We appreciate the thoughtful and careful reviews by three anonymous referees, and the valuable suggestions offered by Roger Edwards (SPC) during an informal review of an earlier version of the manuscript. All of these contributed to a much improved paper.

\section{REFERENCES}

Amburn, S. A., and P. L. Wolf, 1997: VIL density as a hail indicator. Wea. Forecasting, 12, 473-478.

Brock, F. V., K. C. Crawford, R. L. Elliott, G. W. Cuperus, S. J. Stadler, H. L. Johnson, and M. D. Eilts, 1995: The Oklahoma Mesonet: A technical overview. J. Atmos. Oceanic Technol., 12, 5-19.

Brooks, H. E., and J. P. Craven, 2002: A database of proximity soundings for significant severe thunderstorms, 1957-1993. Preprints, 21st Conf. on Severe Local Storms, San Antonio, TX, Amer. Meteor. Soc., 639-642.
- C. A. Doswell III, and M. P. Kay, 2003: Climatological estimates of local daily tornado probability for the United States. Wea. Forecasting, 18, 626-640.

Concannon, P. R., H. E. Brooks, and C. A. Doswell III, 2000: Climatological risk of strong and violent tornadoes in the United States. Preprints, Second Symp. on Environmental Applications, Long Beach, CA, Amer. Meteor. Soc., 212-219.

Coniglio, M. C., and D. J. Stensrud, 2004: Interpreting the climatology of derechos. Wea. Forecasting, 19, 595-605.

Doswell, C. A., III, 1985: Storm scale analysis. Vol. II, The operational meteorology of convective weather, NOAA Tech. Memo. ERL ESG-15, 240 pp.

Galway, J. G., 1989: The evolution of severe thunderstorm criteria within the Weather Service. Wea. Forecasting, 4, 585-592.

Grazulis, T. P., 1993: Significant Tornadoes, 1680-1991. Environmental Films, 1326 pp.

Hales, J. E., Jr., 1993: Biases in the severe thunderstorm data base: Ramifications and solutions. Preprints, 13th Conf. on Weather Analysis and Forecasting, Vienna, VA, Amer. Meteor. Soc., 504-507.

Hart, J. A., 1993: SVRPLOT: A new method of accessing and manipulating the NSSFC severe weather data base. Preprints, 17th Conf. on Severe Local Storms, St. Louis, MO, Amer. Meteor. Soc., 40-41.

Johns, R. H., and W. D. Hirt, 1987: Derechos: Widespread convectively induced windstorms. Wea. Forecasting, 2, 32-49.

Kelly, D. L., J. T. Schaefer, R. P. McNulty, C. A. Doswell III, and R. F. Abbey Jr., 1978: An augmented tornado climatology. Mon. Wea. Rev., 106, 1172-1183.

$\longrightarrow, \ldots$, and C. A. Doswell III, 1985: Climatology of nontornadic severe thunderstorm events in the United States. Mon. Wea. Rev., 113, 1997-2014.

King, P. S. W., 1997: On the absence of population bias in the tornado climatology of southwestern Ontario. Wea. Forecasting, 12, 939-946.

Rasmussen, E. N., and D. O. Blanchard, 1998: A baseline climatology of sounding-derived supercell and tornado forecast parameters. Wea. Forecasting, 13, 1148-1164.

Ray, P. S., P. Bieringer, X. Niu, and B. Whissel, 2003: An improved estimate of tornado occurrence in the central plains of the United States. Mon. Wea. Rev., 131, 1026-1031.

Sammler, W. R., 1993: An updated climatology of large hail based on 1970-1990 data. Preprints, 17th Conf. on Severe Local Storms, St. Louis, MO, Amer. Meteor. Soc., 32-35.

Schaefer, J. T., and R. Edwards, 1999: The SPC tornado/severe thunderstorm database. Preprints, 11th Conf. on Applied Climatology, Dallas, TX, Amer. Meteor. Soc., 603-606.

Silverman, B. W., 1986: Density Estimation for Statistics and Data Analysis. Monographs on Statistics and Applied Probability, No. 26, Chapman and Hall, 175 pp.

Thompson, R. L., R. Edwards, J. A. Hart, K. L. Elmore, and P. Markowski, 2003: Close proximity soundings within supercell environments obtained from the Rapid Update Cycle. Wea. Forecasting, 18, 1243-1261.

Weiss, S. J., and M. D. Vescio, 1998: Severe local storm climatology 1955-1996: Analysis of reporting trends and implications for NWS operations. Preprints, 19th Conf. on Severe Local Storms, Minneapolis, MN, Amer. Meteor. Soc., 536-539.

_ J. J. A. Hart, and P. R. Janish, 2002: An examination of severe thunderstorm wind report climatology: 1970-1999. Preprints, 21st Conf. on Severe Local Storms, San Antonio, TX, Amer. Meteor. Soc., 446-449. 